\title{
Austenitizing Temperature and Cooling Rate Effects on the Martensitic Transformation in a Microalloyed-Steel
}

\author{
Samuel da Silva de Souza $a^{a}$ (1) , Paulo Sérgio Moreira ${ }^{a}$, Geraldo Lúcio de Faria ${ }^{a *}$ (1) \\ ${ }^{a}$ Universidade Federal de Ouro Preto, Campus Universitário do Morro do Cruzeiro, Ouro Preto, MG, Brasil
}

Received: October 15, 2019; Revised: January 10, 2020; Accepted: January 29, 2020

\begin{abstract}
The effects of the austenitizing temperature and the cooling rate upon the kinetic of athermal martensitic transformation in a microalloyed steel were evaluated. Considering the studied steel, the knowledge about these effects on the martensitic transformation has a great relevance for naval manufacturers and steel researchers. In this study, computational simulation was performed aiming to evaluate the phase's stability. Specimens were submitted to quenching simulations in a dilatometer, considering four different austenitizing temperatures and four cooling rates. The results shown that the austenite chemical composition was not significantly affected by the austenitizing temperatures. Both the austenitic grain size and the cooling rate affected the martensitic transformation kinetics. The larger the austenitic grain size, the higher the Ms. The austenitic grain growth promoted a decrease in the required chemical energy to compensate the free energy increase associated with the lattice strain and the creation of new interfaces, leading to a lower austenite undercooling. An extrinsic effect of the cooling rate on the Ms was observed. For lower cooling rates, the carbide precipitation modified que austenite chemical composition, changing its stability and increasing Ms. A predictability equation, correlating the $\mathrm{M}_{\mathrm{S}}$ with the austenite grain size and the steel cooling rate, was proposed.
\end{abstract}

Keywords: Martensitic transformation kinetics, Microalloyed steel, Dilatometry.

\section{Introduction}

Athermal martensitic transformations are usually observed in several types of steels. In this martensitic transformation mode, the martensite fraction does not depend on the holding time in a specific temperature below the $M_{S}$. This behavior is justified by the fact that martensite nucleus activated at a specific temperature $T$, below $M_{S}$, has a growth rate comparable to the sound propagation speed in steels. New nucleation sites are triggered only with complementary cooling ${ }^{1}$.

The available scientific literature highlights that the overall martensitic transformation kinetics is strongly affected by the austenite chemical composition and by the applied cooling rate. They also present that the austenitic grain size has a strong effect on the martensite start temperature, but not on the transformation evolution. However, these effects are verified in different levels for different type of steels ${ }^{2,3}$.

The high strength low alloy steel evaluated in this research is often used in the naval branch. It is characterized as a great hardenable and weldable steel. Due to this, and considering the welding need in the manufacturing process of naval components, the thick plates of this steel are often heat treated (quenching and tempering) and welded ${ }^{4}$.

Considering both quenching heat treatment and welding, it can be stated that the characteristics of the martensitic transformation will have a strong influence on the final

*e-mail: geraldolfaria@yahoo.com.br product quality, as far as the morphology and properties of the martensite, as well as the level of the developed residual stress fields. It is widely accepted that solid-state transformations can significantly affect the residual stress in martensitic products. The $M_{S}$ decrease leads to a reduction of tensile stresses. For sufficient low $M_{S}$ values, compressive-stress fields may occur, which may be followed by an increase of the fatigue resistance.

Besides that, during the welding process, high temperatures are reached in the heat affected zone (HAZ), generally leading to a partial or a complete steel austenitizing ${ }^{1}$. As a consequence of the high cooling rates that can occur in a welding process, in some cases around hundreds of Celsius degrees per second, ${ }^{5}$ the martensitic transformation may take place. Due to the thermal gradients imposed along the HAZ, chemical-composition gradients may occur as well as different austenitic grain sizes and cooling rates can be developed ${ }^{1}$. In short, the austenite to martensite phase decomposition kinetic may locally change.

Considering the presented context, the objective of this work was to contribute promoting a better fundamental understanding about the kinetics of martensitic transformation in an important naval steel. The effects of the austenite grain size and of the cooling rate were evaluated. It is believed that the presented results represent an important data base that may contribute to a better metallurgical understanding of the heat treated and welded products manufactured of the studied steel, being of a great relevance for steel researchers and naval manufacturers. 


\section{Materials and Methods}

\subsection{Characterization of the studied steel}

Table 1 presents the chemical composition of the studied steel. Three devices were used for this evaluation: LECO-CS844 (C and S by infrared absorption after fusion), LECO TC-436DR (N concentration by thermo conductivity after fusion) and Thermo ARL - 4460 (remaining chemical elements by optical emission spectrometry).

It is observed the presence of chemical elements which thermodynamically favor the austenite phase, as Mn and C, and the presence of chemical elements which stabilize the ferrite phase, as $\mathrm{Cr}$, Mo and Ti. Nevertheless, under continuous cooling, all mentioned alloying elements kinetically favor the austenite phase ${ }^{1}$. The presence of good carbide/nitride formers, as Cr, Mo, V and Ti, should also be emphasized.

Figure 1 presents the microstructure of the studied steel in the as manufactured state. It is possible to observe a completely tempered martensite microstructure, as expected for this steel ${ }^{4}$. For this purpose, a sample of the steel in the initial state was etched with Nital $2 \%$ and its microstructure was characterized with a LEICA DM 2700 M light optical microscope.

\subsection{Prediction of the relative stability of phases considering equilibrium conditions}

Carbide/nitride formers are present in the chemical composition of the studied microalloyed steel and they may react with carbon and nitrogen to form precipitates under specific thermodynamic conditions. The thermodynamic stability of these precipitates, for a specific steel chemical composition and considering a constant pressure $\left(1,013 \times 10^{5} \mathrm{~Pa}\right)$, is a temperature function ${ }^{1}$.

Therefore, the chemical composition of the austenite phase, which strongly affects the martensitic transformation kinetics, is also a function of temperature, that is, if some

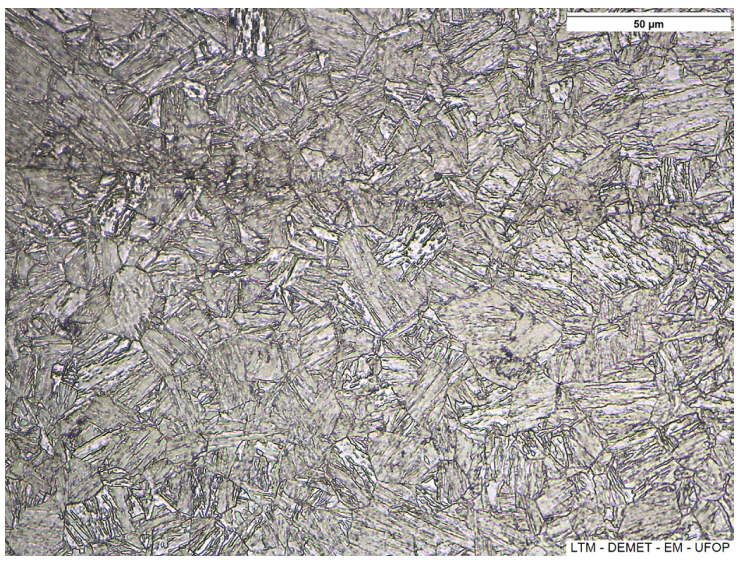

Figure 1. Optical micrograph of the studied steel in the initial state. Nital 2\%. 500x. precipitates dissolve with the austenitizing temperature increase, the solubilized elements will enrich the austenite phase and change the required chemical energy (driving force) to promote de martensitic transformation ${ }^{2}$.

In this context, the relative thermodynamic stability of the phases and precipitates in the equilibrium condition was predicted with the exclusive aim to evaluate if, for the evaluated austenitizing temperatures, a significant change on austenite chemical composition could occur, similarly to performed by Gao et al. ${ }^{2}$. For this purpose, the Matcalc software was applied. The used data base version was mc_fe_v2.057.tdb ${ }^{6}$.

\subsection{Dilatometric tests}

Cylindrical dilatometric samples were machined with $10 \mathrm{~mm}$ in length and $3 \mathrm{~mm}$ in diameter from a $20 \mathrm{~mm}$ thickness steel plate. The tests were performed in a LINSEIS R.I.T.A L78 quenching dilatometer. The vacuum pressure was less than $7.10^{-2}$ bar and the cooling gas was the analytical helium 5.0. The temperature profiles were measured and controlled using thermocouples spot-welded in the middle of the dilatometric samples.

With the aim to evaluate the austenitizing temperature and the prior austenite grain size effects on the martensitic transformation, initially, it was highly important to determine the steel critical cooling rate, i.e. the lowest cooling rate for which martensite is the main product. The critical cooling rate was evaluated for the lowest evaluated austenitizing temperature $\left(920^{\circ} \mathrm{C}\right)$, with a heating rate of $3^{\circ} \mathrm{C} / \mathrm{s}$, a soaking time of 180 seconds and cooling rates of $1^{\circ} \mathrm{C} / \mathrm{s}, 3^{\circ} \mathrm{C} / \mathrm{s}, 5^{\circ} \mathrm{C} / \mathrm{s}$, $10^{\circ} \mathrm{C} / \mathrm{s}, 15^{\circ} \mathrm{C} / \mathrm{s}, 25^{\circ} \mathrm{C} / \mathrm{s}$ and $50^{\circ} \mathrm{C} / \mathrm{s}$. The critical cooling rate was evaluated for this austenitizing condition because the other studied austenitizing temperatures were higher than $920^{\circ} \mathrm{C}$ and, due to that, the steel hardenability would be certainly higher for them ${ }^{1}$.

After determining the steel critical cooling rate, dilatometric tests were performed aiming to evaluate the martensitic transformation kinetics. At this stage, all dilatometric tests were performed using a heating rate of $3^{\circ} \mathrm{C} / \mathrm{s}$. Four austenitizing temperatures were studied $\left(920^{\circ} \mathrm{C}\right.$, $1000^{\circ} \mathrm{C}, 1150^{\circ} \mathrm{C}$ and $1300^{\circ} \mathrm{C}$ ), applying a soaking time of 180 seconds. For each austenitizing temperature, four cooling rates, higher than the critical one, were evaluated $\left(25^{\circ} \mathrm{C} / \mathrm{s}, 50^{\circ} \mathrm{C} / \mathrm{s}, 75^{\circ} \mathrm{C} / \mathrm{s}\right.$ and $\left.100^{\circ} \mathrm{C} / \mathrm{s}\right)$.

The dilatometric data were analyzed using the Origin Pro 9.0 software. The lever rule was applied to the relative length versus temperature data and it was possible to obtain, for each studied condition, the martensite fraction as a function of temperature ${ }^{7}$. The martensite transformation start $\left(M_{S}\right)$ and finish $\left(M_{f}\right)$ temperatures were considered as the ones at which the martensite fractions were equal to $1 \%$ and $99 \%$ respectively. The martensitic transformation rates $(d f / d T)$ were obtained through the first derivation of the martensite fraction versus temperature curves. Curves

Table 1. Chemical composition of the studied steel (wt.\%).

\begin{tabular}{ccccccccccc}
\hline $\mathbf{C}$ & $\mathbf{S i}$ & $\mathbf{M n}$ & $\mathbf{P}$ & $\mathbf{S}$ & $\mathbf{C r}$ & $\mathbf{M o}$ & $\mathbf{N b}$ & $\mathbf{T i}$ & $\mathbf{V}$ & $\mathbf{N}$ \\
\hline 0.1 & 0.3 & 0.9 & 0.02 & 0.003 & 0.7 & 0.5 & 0.005 & 0.02 & 0.04 & 0.005 \\
\hline
\end{tabular}


presenting the martensitic transformation rate as a function of the martensite fraction could then be built.

As previously mentioned, $M_{S}$ is affected by the austenitic grain size, by the applied cooling rate and by the austenite chemical composition ${ }^{2}$. The austenite chemical composition, as will be discussed ahead, was considered unaffected by the studied austenitizing temperatures. Aiming to correlate the effects of the austenitic grain size and of the steel cooling rate on the $M_{S}$ temperature, the Minitab 17 software was used. A multiple linear regression method was applied for this purpose and a statistical predictability equation was proposed.

\subsection{Evaluation of the prior austenite grain size}

Aiming to evaluate the effect of austenitizing temperatures on the prior austenitic grain sizes, the austenitized and quenched samples were etched with Teepol ( $2 \mathrm{~g}$ of picric acid, $1 \mathrm{ml}$ of $\mathrm{HCl}, 100 \mathrm{ml}$ of distillated water and $1 \mathrm{ml}$ of a neutral tensoactive agent). A light optical microscopy LEICA DM 2700M was used to obtain the austenite grain images. The LAS 4.6 software and the automatic equivalent circle diameter method, which is recommended by the ASTM E $1382^{8}$ and ASTM E $112^{9}$ standards, were used to measure the average sizes of the austenitic grains.

\section{Results and Discussion}

\subsection{Prediction of the relative stability of phases considering Equilibrium conditions}

Figure 2 presents the computational simulation results related to the thermodynamic stability of phases and precipitates for the studied steel. According to the obtained results, the $\mathrm{VC}, \mathrm{Fe}_{3} \mathrm{C}$ and $\mathrm{M}_{6} \mathrm{C}(\mathrm{M}=\mathrm{Mo}, \mathrm{Cr}$ or $\mathrm{V})$ precipitates are completely dissolved in temperatures below $900^{\circ} \mathrm{C}$. Above this temperature, the microstructure will be mainly composed of austenite and TiN precipitates. Considering the standardized relatively low heating rate and the great soaking time used in this study, it is reasonable to suppose that, for the evaluated austenitizing temperatures $\left(920^{\circ} \mathrm{C}, 1000^{\circ} \mathrm{C}\right.$, $1150^{\circ} \mathrm{C}$ and $1300^{\circ} \mathrm{C}$ ) there is not significant differences in the austenite chemical compositions immediately after the austenitizing procedure ${ }^{2}$.

According to preview studies, the austenitizing temperature does not directly affect the kinetics of martensitic transformation. However, the changes produced by it, either on the austenite chemical composition (precipitation/dissolution of phases) or in the austenite grain size, do it; and must be considered ${ }^{3,10,11}$.

\subsection{Critical cooling rate}

Figures 3 and 4 present the relative length versus temperature data obtained for the samples submitted to the evaluated cooling rates. For $25^{\circ} \mathrm{C} / \mathrm{s}$ and $50^{\circ} \mathrm{C} / \mathrm{s}$, a linear behavior can be observed from Ms until $920^{\circ} \mathrm{C}$, indicating that for these cooling rates, no transformation beyond the martensitic, that promotes significant volumetric changes, happened. On the other hand, lowering the cooling rate, it was possible to observe a deviance from the abovementioned linear behavior, which indicates the formation of diffusional products, as bainite ${ }^{1,7}$.

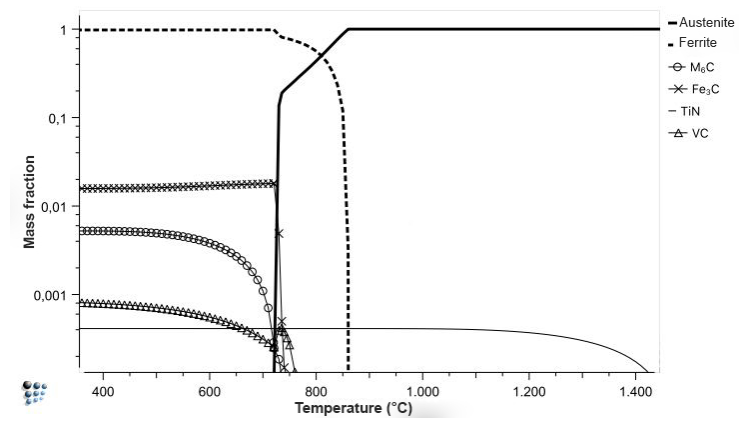

Figure 2. Relative thermodynamic stability of phases in equilibrium condition for the studied microalloyed steel.

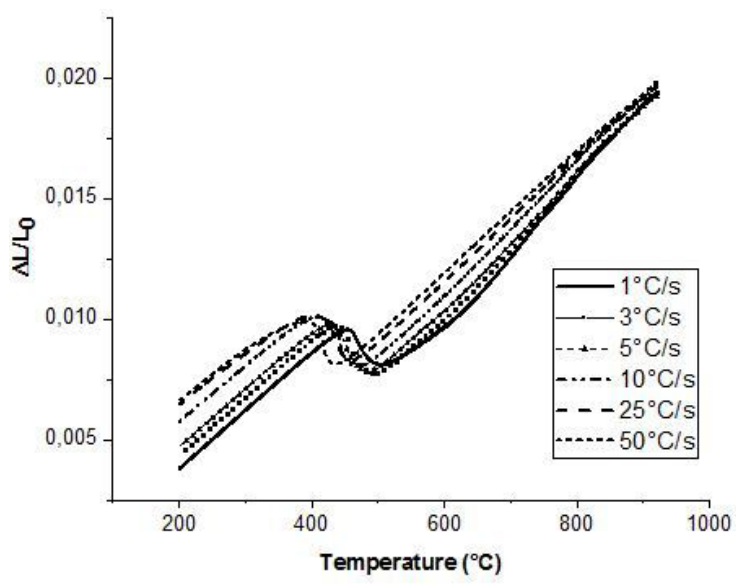

Figure 3. Curves of relative sample length versus temperature for samples austenitized at $920^{\circ} \mathrm{C}$ and cooled with different rates.

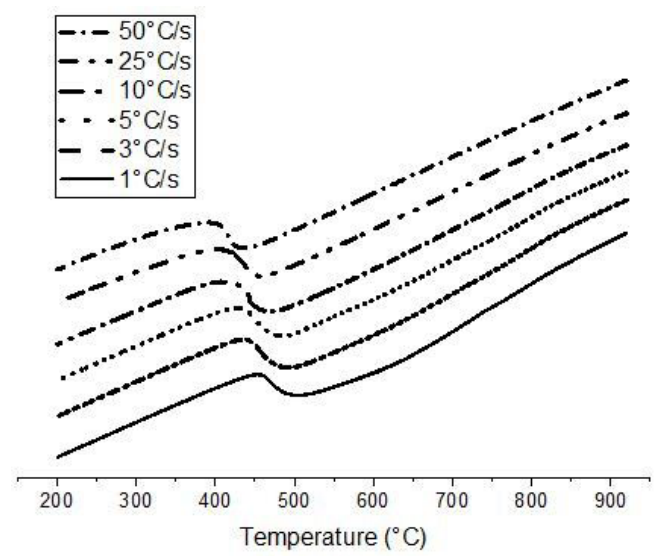

Figure 4. Separately presented curves of relative sample length as a function of temperature for samples austenitized at $920^{\circ} \mathrm{C}$ and cooled with different cooling rates.

Considering these observations, it was assumed that the critical cooling rate is lower than $25^{\circ} \mathrm{C} / \mathrm{s}$. Aiming to confirm this assumption, the sample submitted to the $25^{\circ} \mathrm{C} / \mathrm{s}$ cooling rate was metallographic prepared, etched with Nital $2 \%$ and characterized using a VEGA 3 Tescan scanning electron microscope (Figure 5). The microstructure, as expected, is composed of lath-like martensite ${ }^{12}$. 


\subsection{Effect of the austenite grain size on the martensitic transformation kinetics}

Figures 6-13 are micrographs that present the austenitic grains and its size distribution for each studied austenitizing temperature. It is possible to observe that the increase of the austenitizing temperature led to the increase of the average austenitic grain size. Figure 14 summarizes the effect of the austenitizing temperature on the prior austenite grain size, highlighting that the lower average grain size was $12 \mu \mathrm{m}$ at $920^{\circ} \mathrm{C}$ and the higher one was $71 \mu \mathrm{m}$ at $1300^{\circ} \mathrm{C}$. As the austenitic grain boundaries are high energy interfaces (grain growth driving force), aiming to reach a minimum energy state, the austenitic grains spontaneously grow with the temperature increase. Larger grains grow consuming surrounding finer ones ${ }^{1}$.

Nevertheless, second phase particles lead to the creation of local pinning forces which effectively restrict the grain boundary motion and consequently the grain growth ${ }^{1,13}$. As the studied austenitizing temperatures were not high enough to promote the complete dissolution of the precipitates, i.e. titanium nitrides still stable, a relatively heterogeneous austenitic grain size distribution (local pinning forces) was verified. This is well characterized by the relatively high standard deviations ${ }^{13}$.

Table 2 and Figure 15 present the effects of the prior austenitic grain size (PAGS) on the martensite start $\left(M_{S}\right)$ and finish $\left(M_{f}\right)$ temperatures. It is noticed that the higher the austenite grain size, the higher the $M_{S}$ and $M_{f}$ temperatures.

The martensitic transformation starts only if the change in chemical free energy between the austenite and martensite phases becomes high enough to overcome the non-chemical free energy involved in the transformation. This non-chemical free energy is associated to the sum of the required energies to accomplish the lattice shear strain (due to the martensite nucleation), the remaining austenite strain (aiming to accommodate the higher molar volume of martensite crystals) and the creation of new interfaces ${ }^{3,14,15}$.

Previous studies state that if there is any increase in constraints to the austenitic matrix deformation, an increase of the required energy to plastically deform the austenite during the martensite nucleation will be observed. Some authors claim that the decrease of the austenitic grain size can be one of these constraints factors ${ }^{11,15-17}$. Due to theses constraints factors, the chemical driving force required for the occurrence of the martensitic transformation increases, promoting the decrease of $M_{S}$ temperatures ${ }^{3,10,16,17}$.

Table 2. Martensite start and finish temperatures as a function of average PAGS and applied cooling rate.

\begin{tabular}{|c|c|c|c|c|c|c|c|c|}
\hline \multirow{3}{*}{ 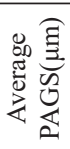 } & \multicolumn{8}{|c|}{ Cooling rate $\left({ }^{\circ} \mathrm{C} / \mathrm{s}\right)$} \\
\hline & \multicolumn{2}{|c|}{$25^{\circ} \mathrm{C} / \mathrm{s}$} & \multicolumn{2}{|c|}{$50^{\circ} \mathrm{C} / \mathrm{s}$} & \multicolumn{2}{|c|}{$75^{\circ} \mathrm{C} / \mathrm{s}$} & \multicolumn{2}{|c|}{$100^{\circ} \mathrm{C} / \mathrm{s}$} \\
\hline & $M_{S}$ & $M_{f}$ & $M_{S}$ & $M_{f}$ & $M_{S}$ & $M_{f}$ & $M_{S}$ & $M_{f}$ \\
\hline 12 & 484 & 333 & 457 & 311 & 446 & 304 & 436 & 293 \\
\hline 24 & 488 & 350 & 474 & 312 & 461 & 303 & 441 & 300 \\
\hline 33 & 516 & 364 & 484 & 314 & 463 & 312 & 452 & 306 \\
\hline 71 & 528 & 372 & 502 & 341 & 471 & 332 & 458 & 317 \\
\hline
\end{tabular}

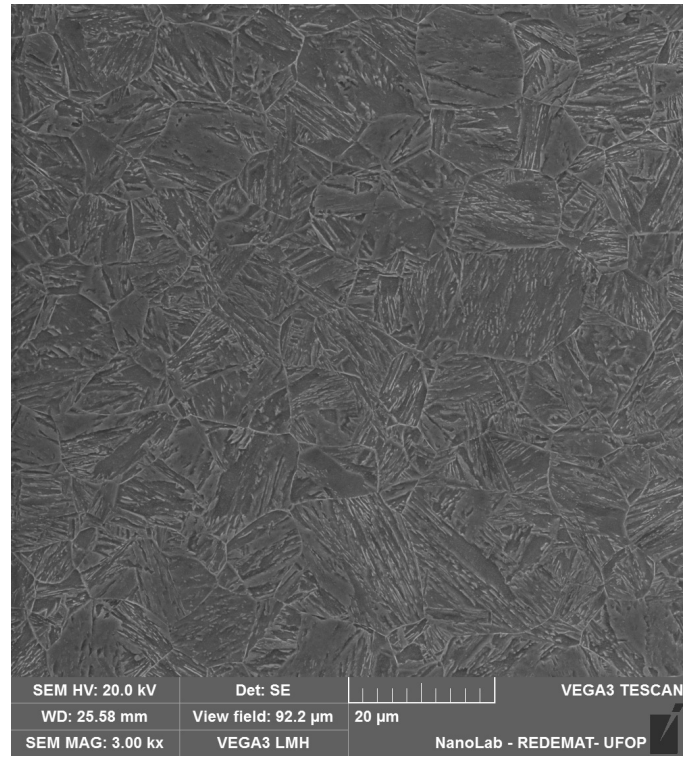

Figure 5. Microstructure of the studied steel austenitized at $920^{\circ} \mathrm{C}$ and cooled at $25^{\circ} \mathrm{C} / \mathrm{s}$ rate. Nital $2 \% .3000 \mathrm{x}$.

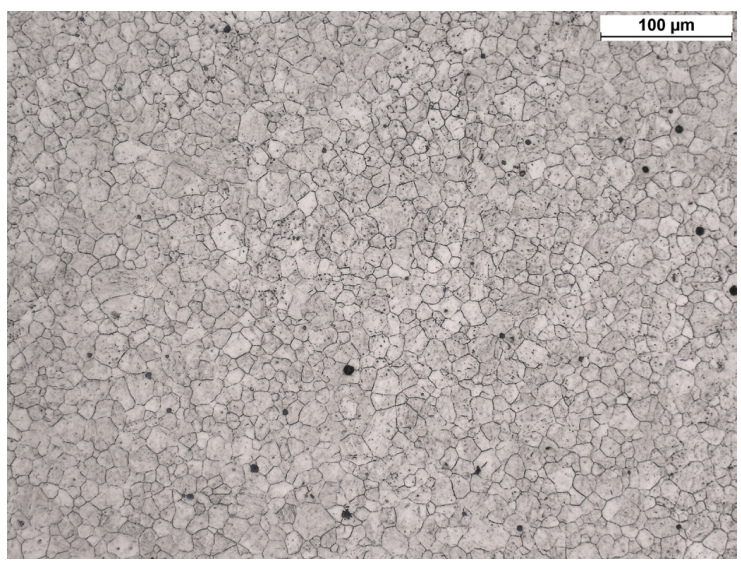

Figure 6. Prior austenitic grains for the austenitizing temperature of $920^{\circ}$ C. Etchant: Teepol. OM. 200x.

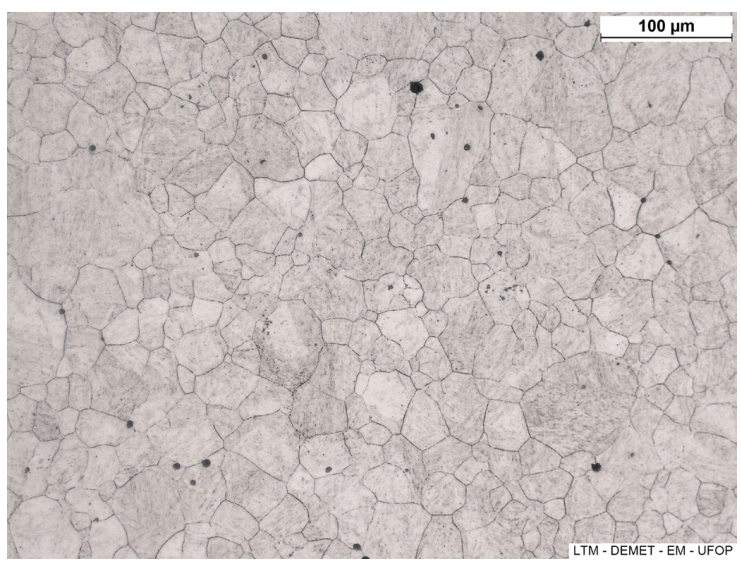

Figure 7. Prior austenitic grains for the austenitizing temperature of $1000^{\circ} \mathrm{C}$. Etchant: Teepol. OM. 200x. 


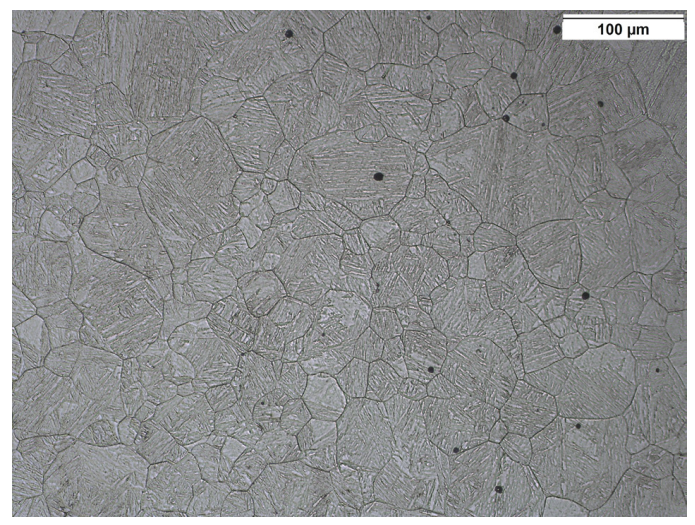

Figure 8. Prior austenitic grains for the austenitizing temperature of $1150^{\circ} \mathrm{C}$. Etchant: Teepol. OM. 200x.

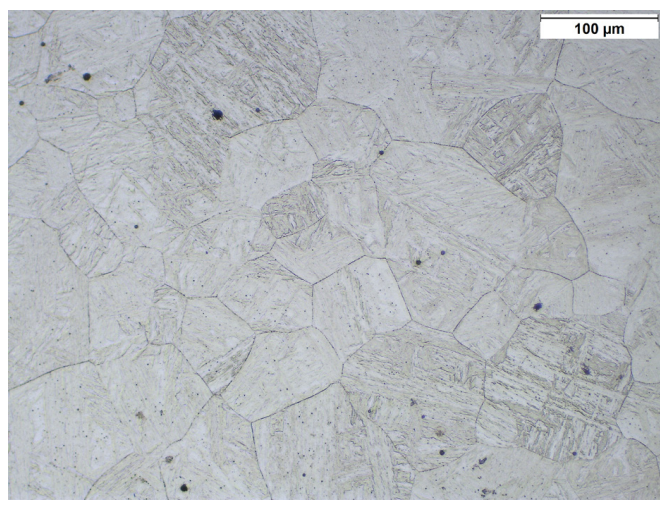

Figure 9. Prior austenitic grains for the austenitizing temperature of $1300^{\circ} \mathrm{C}$. Etchant: Teepol. OM. 200x.

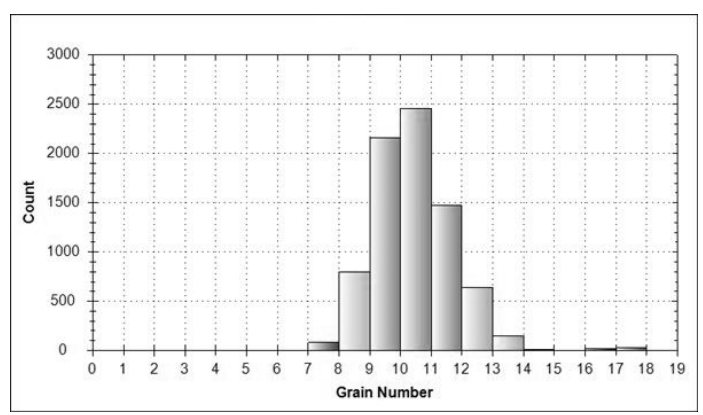

Figure 10. Grain size distribution for the austenitizing temperature of $920^{\circ} \mathrm{C}$.

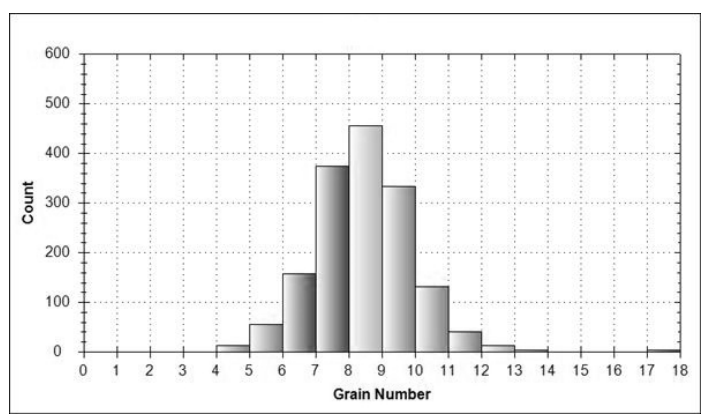

Figure 11. Grain size distribution for the austenitizing temperature of $1000^{\circ} \mathrm{C}$.

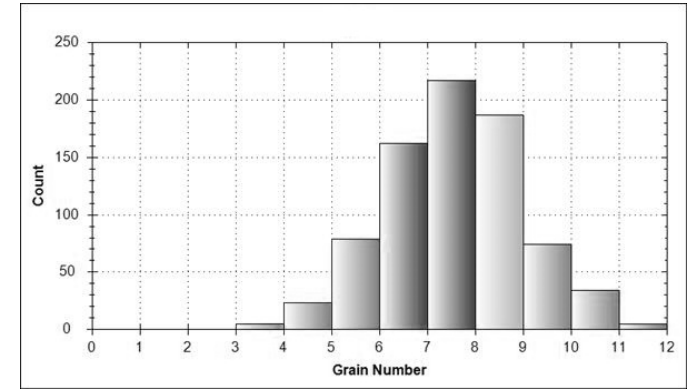

Figure 12. Grain size distribution for the austenitizing temperature of $1150^{\circ} \mathrm{C}$

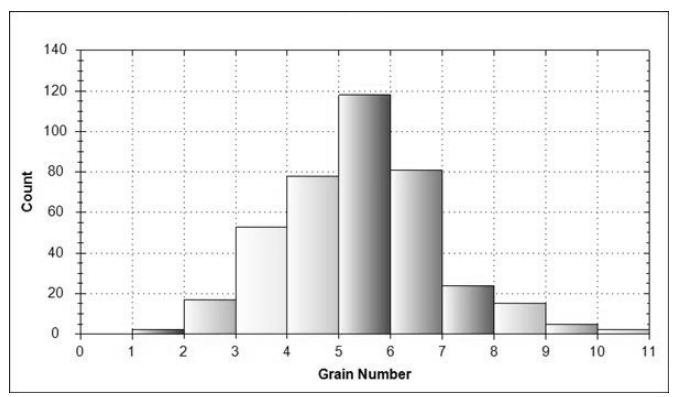

Figure 13. Grain size distribution for the austenitizing temperature of $1300^{\circ} \mathrm{C}$.

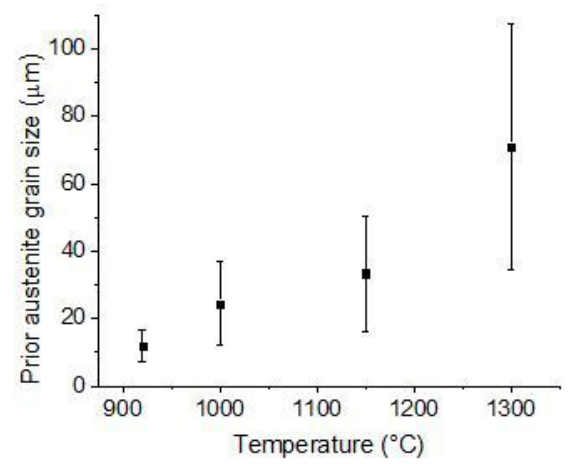

Figure 14. Prior austenite grain size (PAGS) as a function of austenitizing temperature.

Considering the above presented information and the obtained results, (Table 2 and Figure 15), it is possible to assume that, for the studied steel, as the austenitizing temperature and the austenitic grain size increased, the constraints to the austenite plastic deformation decreased. Therefore, there is a decrease of the required driving force for the martensitic transformation beginning, leading to a decrease of the austenite undercooling, i.e to an increase of the $M_{S}$ temperature.

From a fundamental point of view, the $M_{f}$ temperature is not a meaningful concept because the martensitic transformation progresses only with the undercooling increase. As a principle, it never reaches the completion due to a stabilization effect ${ }^{14}$.

The effect of the austenitic grain size upon the martensitic transformation rate, for the cooling rate of $25^{\circ} \mathrm{C} / \mathrm{s}$, is shown if Figure 16. For all austenitizing temperatures, it is noticed that the martensitic transformation rate increases in accordance with 
the martensite fraction increase until it reaches a maximum value, from which it begins to decrease. According to previous studies, the martensite transformation is mainly controlled by the nucleation stage and it strongly depends on the autocatalytic effect. At the beginning of the martensitic transformation, the martensite nucleus are preferentially formed at lattice stacking faults and, as the martensite molar volume is higher than the austenite one, when a nucleus are formed, it strains de surrounding austenite, increasing its dislocation density. These dislocations form new preferential sites for martensite nucleation, and initially, the transformation rate increases. However, the increase of dislocation density promotes the austenite work hardening, increasing the required energy to deform it and negatively affecting the transformation rate. When this effect overcomes the autocalysis, the transformation rate decreases ${ }^{3,11,14}$.

It is observed that the martensitic transformation rate was not strongly affected by the austenitic grain size. Bohemen and Siestma observed a similar behavior for a Fe-0.8C steel. They affirmed this happens because the austenitic grain boundaries do not represent preferential sites for martensite nucleation, but the dislocation do $\mathrm{it}^{3}$. According to Pradhan and Ansell, the martensitic transformation rate is a function of two parameters: a) the temperature derivative of the driving force $\left(d \Delta G_{C}^{\gamma \rightarrow \alpha^{\prime}} / d T\right)$ which controls the increasing driving force available for transformation with falling temperature; b) the deformation energy at $M_{S}$ which controls the introduction of autocatalytic martensite nucleus into the distorted regions of surrounding austenite lattice. Increasing either of these two factors leads to an increase in transformation rate ${ }^{11}$.

For the same austenite chemical composition, i.e. there is no significant influence on the $\left(d \Delta G_{C}^{\gamma \rightarrow \alpha^{\prime}} / d T\right)$. If the austenite grain size do not significantly influence the autocatalytic effect, it is expected that there is not significant influence of the austenite grain size on the transformation rate. As previously presented, for the studied steel, there is no significant chemical composition differences between the obtained austenite for each austenitizing temperature. Therefore, there is no significant influence on the $\left(d \Delta G_{C}^{\gamma \rightarrow \alpha^{\prime}} / d T\right)$ and probably neither on the autocatalytic phenomenon.

In this context, the obtained results (Figure 16) agree with the widely accepted statement that grain boundaries and grain corners are not preferential martensitic nucleation sites $^{3}$. Regarding the effect of the strain energy, it is known that its contribution on the $M_{S}$ temperature increases with the austenite grain size decrease ${ }^{16}$. But, according to Bohemen and Siestma, exactly at the transformation beginning, the first formed martensite laths in a large austenitic grained structure have a greater effect to increase the plastic deformation strength of the remaining austenite than the first formed martensitic units in a refined microstructure. This is due to the fact that martensitic units with larger aspect ratios (i.e., width/length) have higher strain energies. Thus, the deformation strength of the remained austenite as a function of the transformed martensite fraction increases in the transformation beginning with coarsening the austenitic structure. After some amount of the austenite phase have transformed into martensite, the remaining austenite mechanical strength is not going to be strongly affected by the prior austenitic grain size. Shortly, the austenitic grain size strongly affects the start of the martensitic transformation, i.e. $M_{S}$, but not strongly the evolution of the transformation. This well explain the studied steel behavior ${ }^{3}$.

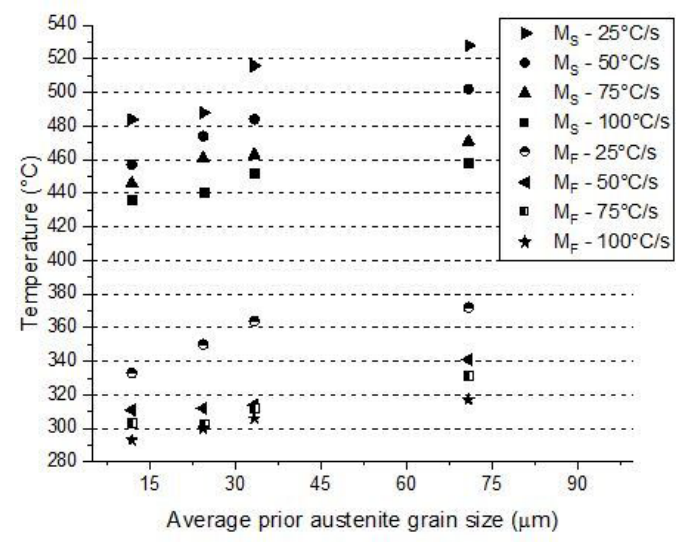

Figure 15. Effect of the austenite grain size upon the martensite start and finish temperatures.

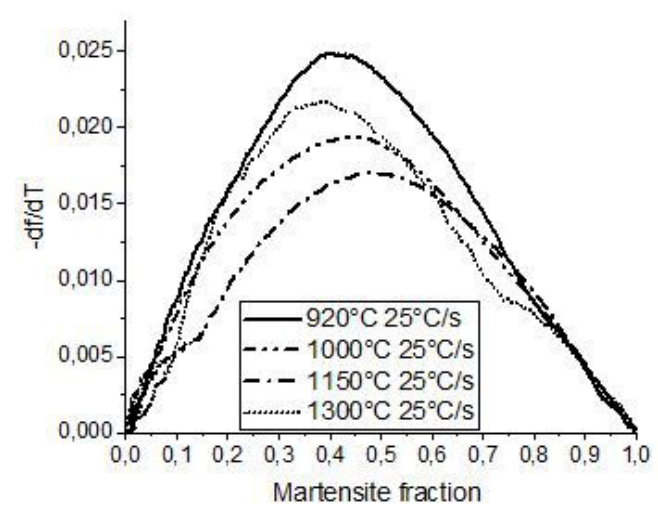

Figure 16. Martensitic transformation rate as a function of the of the martensite fraction for different austenitizing temperatures.

\subsection{Effect of cooling rate on the kinetics of martensitic transformation}

The cooling rate effect on the $M_{S}$ and $M_{f}$ temperatures, for each studied austenitizing temperatures, is presented in Figure 17. For all studied conditions, it is possible to observe that the cooling rate increase led to the $M_{S}$ and $M_{f}$ temperatures decrease. Despite the existence of similar results in the literature, a fulfilling explanation of the underlying cause of the cooling rate effect upon $M_{S}$ has not been found, but only some hypotheses.

Many authors highlight that if martensitic transformation is athermal, the steel cooling rate should no influence the critical temperatures neither the transformation evolution. However, some authors have found experimental evidences showing the significant effect of this variable $2,15,18-24$.

Some authors have verified similar results to those obtained in this study, i.e. the cooling rate increase promoting the $M_{S}$ decrease. Gao et al. ${ }^{2}$ verified it studying a ferritic $9 \mathrm{Cr}-1.7 \mathrm{~W}-0.4 \mathrm{Mo}-\mathrm{Co}$ steel and attributed the phenomenon to restraining of the martensitic transformation caused by the cooling rate increase. According to them, the studied steel is strongly susceptible to carbide precipitation from austenite, mainly for low cooling rates. In this context, for higher cooling rates, the precipitation phenomenon is 


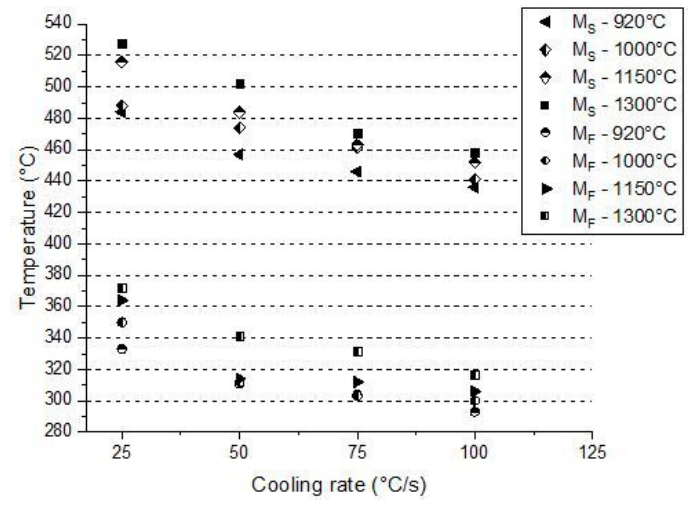

Figure 17. Effect of the cooling rate upon the martensitic start and finish temperatures for the austenitizing temperature of $920^{\circ} \mathrm{C}$.

inhibited, and the austenite becomes richer in solute atoms, leading to $M_{S}$ decrease.

Therefore, it is possible to affirm that, for some steels, the cooling rate decrease can favor carbide precipitation from the undercooled austenite, prior to the martensitic transformation, changing the austenite chemical composition and, consequently, affecting the $M_{S}$ temperature. Alvarez et al. ${ }^{18}$ and Alvarez and Garcia $^{19}$ verified this phenomenon in four martensitic stainless steels. They measured the total area occupied by carbides in the martensitic microstructures of quenched steels. The obtained data indicated that the carbide fraction in the martensitic microstructures increased with the cooling rate decrease, while $M_{S}$ temperatures simultaneously increased. Considering the precipitation phenomenon, the decrease of carbide former elements and also the carbon content in the austenite solid solution lead to higher values of $M_{S}{ }^{18,19}$.

According to Zhao and Notis ${ }^{20}$, the $M_{S}$ temperature is independent of the cooling rate only if the martensite crystals forms directly from the original austenite, without the formation of diffusional constituents during the steel cooling. According to them, this happens, because de austenite chemical composition is not changed during its undercooling.

According to Tsai et al. ${ }^{21}$, the cooling rate increase can also promote an increase of the quenched-in vacancies amount. The higher the vacancies density, the higher the austenite strengthen. Therefore, the required chemical driving force for martensitic transformation would increase, leading to lower $M_{S}$ values. These authors used this assumption to explain the decrease of the $M_{S}$ temperature with the cooling rate increase, up to $100^{\circ} \mathrm{C} / \mathrm{s}$, in a AISI 410 stainless steel.

However, for some steels, the cooling rate decrease leads to the $M_{S}$ temperature decrease. This was verified is steels in which the martensitic transformation is preceded by the formation of bainite, ferrite or perlite. The formation of these constituents before the martensitic transformation promotes a carbon partitioning, enrichening the austenite in carbon and stabilizing $i^{22,23}$. Zhao and Notis $^{20}$ presented experimental data concerned to the 0.35C-1.4Mn-0.76Si-0.19Mo-0.07Cr-0.06Ni-0.16V steel in which the aforementioned phenomenon was verified in a range of cooling rates where the martensitic transformation occurred after the occurrence of bainite formation. As the cooling rate was decreased, the fraction of diffusional products previously formed to the martensitic transformation increased; consequently, the remaining austenite became stabilized and therefore $M_{S}$ decreased.
Lastly, some steels can even present both situations: a cooling rate interval in which $M_{S}$ decreases with the cooling rate increase; and another in which $M_{S}$ decreases with the cooling rate decrease ${ }^{24}$. It is clear, thus, that the cooling rate does not directly affect the $M_{S}$ temperature, but instead it affects different diffusional phase transformation mechanisms, which can alter the stability of the austenite phase. Therefore, it is possible to affirm that the steel cooling rate has not an intrinsic effect upon the martensitic transformation, but it has an extrinsic one. For the studied steel, it is clear that the austenite phase's stability is enhanced with the cooling rate increase. However, it was not possible to experimentally identify which mechanism acted.

As the studied steel has great carbide formers on its chemical composition, it is supposed that the same causes raised by Alvarez and Garcia ${ }^{19}$ can be stated here. Considering the studied steel chemical composition and the thermodynamic equilibrium, it is possible to affirm that chromium and molybdenum carbides $\left(\mathrm{M}_{6} \mathrm{C}\right)$ start their precipitation around $730^{\circ} \mathrm{C}$ in the austenitic matrix (Figure 2). As it is well known, the steel cooling rate affect these precipitation kinetics. It is expected that the higher the cooling rate, the lower the precipitates amount.

In this context, it is supposed that for low cooling rates, if chromium and molybdenum carbides precipitate (very hard to detect with the dilatometric device), the chromium, molybdenum and carbon contents in the remaining austenite would decrease, anticipating the martensitic transformation, i.e. increasing the Ms temperature ${ }^{19,20}$. For the studied steel, this is a great hypotheses based on the above mentioned previous studies and the obtained experimental evidences that highlights: 1) For all studied cooling rates, diffusional constituents as ferrite, pearlite and bainite, which could decrease Ms temperature, do not form in studied steel; 2) The studied steel is highly susceptible to fine carbide precipitation.

The effect of the cooling rate on the martensitic transformation rate is presented in Figure 18 for the austenitizing temperature of $920^{\circ} \mathrm{C}$. It was observed that the cooling rate increase promoted the increase of the martensitic transformation rate. Gao et al. verified the same phenomenon in the ferritic 9Cr-1,7W-0,4Mo-Co steel ${ }^{25}$.

As previously discussed, the transformation rate is affected by the temperature derivate of the driving force for martensitic transformation and by the strain energy at $M_{S}$. Regarding the curve profiles presented in Figure 18, it is possible to affirm that the driving force for the martensitic transformation at $M_{S}$ may follow the same discussed trend. Conversely, the deformation energy at $M_{S}$ increases with $M_{S}$ decrease $^{11}$.

The results presented in Figure 18 show that the steel cooling rate increase, in general, implies in the transformation rate increase. This means that in spite of the effect of the increasing deformation energy, which constraints the martensitic transformation by strengthen the austenite, the dominant effect is the autocatalytic $\mathrm{c}^{3,11,14}$.

The increase of the martensitic transformation rate combined with the cooling rate increase generate two effects: 1) the increase of the martensitic nucleation rate, due to an enhanced autocatalytic effect; 2) the significant decrease of the average volume of martensitic units due to a great austenite work hardening ${ }^{25}$. The combination of these factors may be the reason why the martensitic transformation rate peaks 


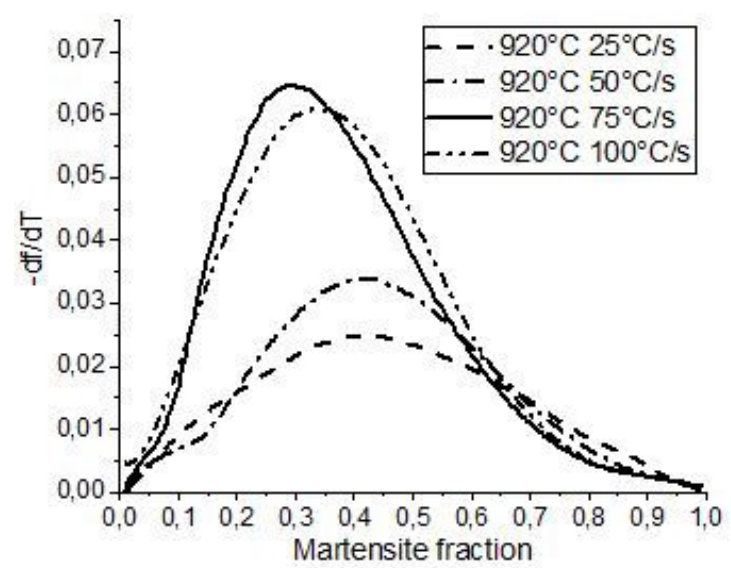

Figure 18. Martensitic transformaion rate as a function of the cooling rate. Austenitizing temperature of $920^{\circ} \mathrm{C}$.

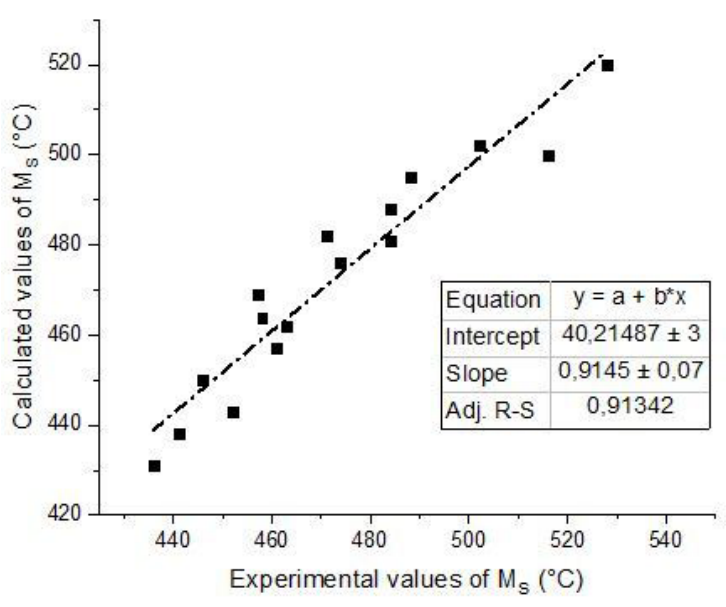

Figure 19. Calculated (Equation 1) versus experimental values of $M_{S}$. occurred for lower martensite fractions for higher cooling rates (Figure 18). It is important to highlight that the effect of the cooling rate upon the martensitic transformation rate becomes almost inexistent for high cooling rates, as also observed by Gao et al. ${ }^{25}$.

\subsection{Modeling of martensite start temperature}

The martensite start temperature is a parameter of great importance on the prediction of residual stresses in welded joints ${ }^{26}$. Many equations which aim to evaluate $M_{S}$ as a function of the chemical composition are available in the literature ${ }^{27}$. Unfortunately, these equations generally do not consider the effects of cooling rate and austenitic grain size upon $M_{S}$. Hence, the obtained results can differ significantly from the experimental ones.

Table 3 presents the martensite start temperature calculated for the studied steel by some equations available in the technical literature, considering only its chemical composition. It can be seen that the obtained values, which vary from $451^{\circ} \mathrm{C}$ to $490^{\circ} \mathrm{C}$, are in a much narrower range than the experimental values presented in Table 2 , that vary from $436^{\circ} \mathrm{C}$ to $528^{\circ} \mathrm{C}$.

It was realized the possibility of describing the martensite start temperature as a function of the average prior austenitic grain size and of the applied cooling rate (Equation 1) for the studied steel. This equation was statistically obtained using the multiple linear regression method, as already described in Materials and Methods.

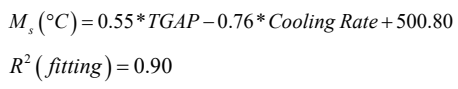

It can be seen that the coefficients of the average prior austenite grain size (PAGS) and of the cooling rate are related with the physical phenomena that influence $M_{S}$. Thus, an increase in austenitic grain size leads to an increase in $M_{S}$. Conversely, an increase in the cooling rate leads to a decrease in $M_{S}$.

Figure 19 compares the values experimentally obtained by dilatometry (points) with the ones calculated with the use of the Equation 1 (dashed line). As expected, a great linear relationship was observed.

Table 3. Martensite start temperature calculated for the studied steel applying empirical equations available in the literature ${ }^{27}$.

\begin{tabular}{lc}
\hline \multicolumn{1}{c}{ Equations } & $M_{S}\left({ }^{\circ} \mathrm{C}\right)$ \\
\hline $\mathbf{M}_{\mathbf{S}}=499-308 \% \mathrm{C}-32.4 \% \mathrm{Mn}-27 \% \mathrm{Cr}-16.2 \% \mathrm{Ni}-10.8 \% \mathrm{Si}-10.8 \% \mathrm{~W}$ & 473 \\
\hline $\mathbf{M}_{\mathbf{S}}=499-324 \% \mathrm{C}-32.4 \% \mathrm{Mn}-27 \% \mathrm{Cr}-16.2 \% \mathrm{Ni}-10.8 \% \mathrm{Si}-10.8 \% \mathrm{Mo}-10.8 \% \mathrm{~W}$ & 471 \\
\hline $\mathbf{M}_{\mathbf{S}}=538-350 \% \mathrm{C}-37.7 \mathrm{Mn}-37.7 \mathrm{Cr}-18.9 \mathrm{Ni}-27 \mathrm{Mo}$ & 451 \\
\hline $\mathbf{M}_{\mathbf{S}}=499-292 \% \mathrm{C}-32.4 \% \mathrm{Mn}-22 \% \mathrm{Cr}-16.2 \% \mathrm{Ni}-10.8 \% \mathrm{Si}-10.8 \% \mathrm{Mo}$ & 490 \\
\hline $\mathbf{M}_{\mathbf{S}}=561-474 \% \mathrm{C}-33 \% \mathrm{Mn}-17 \% \mathrm{Cr}-17 \% \mathrm{Ni}-21 \% \mathrm{Mo}$ & 459 \\
\hline $\mathbf{M}_{\mathbf{S}}=539-423 \% \mathrm{C}-30.4 \% \mathrm{Mn}-12.1 \% \mathrm{Cr}-17.7 \% \mathrm{Ni}-7.5 \% \mathrm{Mo}$ & 478 \\
\hline $\mathbf{M}_{\mathbf{S}}=550-361 \% \mathrm{C}-39 \% \mathrm{Mn}-20 \% \mathrm{Cr}-17 \% \mathrm{Ni}-5 \% \mathrm{Mo}-5 \% \mathrm{~W}-35 \% \mathrm{~V}-10 \% \mathrm{Cu}-30 \% \mathrm{Al}$ & 472 \\
\hline $\mathbf{M}_{\mathbf{S}}=538-317 \% \mathrm{C}-33 \% \mathrm{Mn}-28 \% \mathrm{Cr}-17 \% \mathrm{Ni}-11 \% \mathrm{Si}-11 \mathrm{Mo}-11 \% \mathrm{~W}$ & 470 \\
\hline
\end{tabular}




\section{Conclusions}

The kinetics of martensitic transformation was studied in a high strength low alloy steel applying the dilatometry technique. The following conclusions are drawn:

For the studied steel, the increase of the average austenitic grain size led to the increase of the $M_{S}$ temperatures. For a specific austenitizing temperature and for the studied cooling rate range, $M_{S}$ decreased with increasing cooling rate.

The prior austenite grain size did not affect the martensite transformation rate significantly. However, the martensitic transformation rate increased in accordance with the cooling rate increase.

For a given austenitizing temperature, the highest martensitic transformation rates presented a tendency of occurring for lower martensite fractions. This may be due to an enhanced austenite deformation energy because of the cooling rate increase.

The kinetics reasoning indicates that the martensitic transformation kinetics in the studied steel is not directly affected by the cooling rate (there is not an intrinsic effect), but instead by its effect upon the austenite phase's stability (there is an extrinsic effect).

For the studied steel, an equation correlating the average prior austenitic grain size and the cooling rate to $M_{S}$ was obtained using the multiple linear regression method. This result may be of great interest in the prediction of the Ms temperature considering situations in which the studied steel may be hot processed.

\section{Acknowledgment}

The authors thank the Conselho Nacional de Desenvolvimento Científico e Tecnológico (CNPq) for the financial support.

\section{References}

1. Bhadeshia HK, Honeycombe RW. Steels: microstructure and properties. 3rd ed. Amsterdam: Elsevier; 2006.

2. Gao Q, Wang C, Qu F, Wang Y, Qiao Z. Martensite transformation kinetics in 9Cr-1.7W-0.4Mo-Co ferrite steel. J Alloys Compd. 2014;610:322-30

3. van Bohemen SMC, Sietsma J. Kinetics of martensite formation in plain carbon steels: critical assessment of possible influence of austenite grain boundaries and autocatalysis. Mater Sci Technol. 2014;30(9):1024-33.

4. USIMINAS. Heavy plates [cited 2019 Oct 15]. Available from: https://www.usiminas.com/wp-content/uploads/2013/11/us0073-15j-chapas-grossas-ing.pdf

5. Poorhaydari BY, Patchett BM, Ivey DG. Estimation of cooling rate in the welding of plates with intermediate thickness. Weld J. 2005;84(10):149-55.

6. Kozeschnik E, Buchmayr B. MatCalc - A simulation tool for multi-componentthermodynamics, diffusion and phase transformation kinetics. In Kozeschnik E, Buchmayr B. Mathematical modelling of weld phenomena. Vol. 5. London: Institute of Materials; 2001. p. 349-361.
7. Motycka P, Köver M. Evaluation methods of dilatometer curves of phase transformation. Czech Republic: COMAT; 2012.

8. ASTM International. E1382-97. Standard Test Methods for Determining Average Grain Size Using Semiautomatic and Automatic Image Analysis. West Conshohocken (PA): ASTM International; 2015.

9. ASTM International. E112-12. Standard Test Methods for Determining Average Grain Size. West Conshohocken (PA): ASTM International; .

10. Brofman PJ, Ansell GS. On the effect of fine grain size on the Ms temperature in Fe-27Ni-0,025C alloys. Metall Trans, A, Phys Metall Mater Sci. 1983;14A(9):1929-31.

11. Phadham R, Ansell G. Kinetics of the martensite transformation in athermal Fe-C-Ni-Cr alloys. Metall Trans, A, Phys Metall Mater Sci. 1978;9A(6):793-801.

12. Krauss G. Steels: processing, structure and performance. Ohio (OH): ASM International; 2005.

13. Wang SC. The effect of titanium and reheating temperature on the microstruture and strength of plain carbon, vanadium and niobium microalloyed steels. J Mater Sci. 1990;25(1):187-93.

14. Khan S, Bhadeshia HK. Kinetics of martensitic transformation in partially bainitic 300M steel. Mater Sci Eng A. 1990;129(2):25772.

15. Nishiyama Z. Martensitic transformation. New York (NY): Academic Press; 1978.

16. Breinan EM, Ansell GS. The influence of austenite strength upon the austenite-martensite transformation in alloy steels. Metall Trans, B, Process Metall. 1970;1:1513-20.

17. Yang H, Bhadeshia HK. Austenite grain size and the martensite start temperature. Sri Mater. 2008;60(7):493-5.

18. Alvarez LF, Garcia C, Lopez V. Continuous cooling transformations in martensitic stainless steels. ISIJ Int. 1994;34(6):516-21.

19. Alvarez LF, Garcia C. Optimization of the properties obtained by quenching in martensitic stainless steels $\mathrm{X}-30-40 \mathrm{Cr} 13$ and X40-60CrMoV14. J Mater Sci. 1993;28(5):1264-8.

20. Zhao JC, Notis MR. Continuous cooling transformation kinetics versus isothermal transformation kinetics of steels: a phenomenological rationalization of experimental observations. Mater Sci Eng Rep. 1995;15(4-5):135-208.

21. Tsai MC, Chiou CS, Du JS, Yang JR. Phase transformations in AISI 410 stainless steel. Mater Sci Eng A. 2002;332(1-2):1-10.

22. Wang J, Wolk PJ, Zwaag S. Effects of carbon concentration and cooling rate on continuous cooling transformations predicted by artificial neural network. ISIJ Int. 1999;39(10):1038-46.

23. Van Bohemen SMC, Sietsma J. Martensite formation in partially and fully austenitic plain carbon steels. Metall Mater Trans, A Phys Metall Mater Sci. 2009;40(5):1059-68.

24. Meza MA, Sanchez EG, Alvarado O, Rodriguez A, Mata MP, Colás R. Effect of the high-temperature deformation on the Ms temperature in a low C martensitic stainless steel. J Mater Eng Perform. 2013;22(2):345-50.

25. Gao Q, Liu Y, Di X, Yu L, Yan Z. Martensite transformation in the modified high $\mathrm{Cr}$ ferritic heat-resistant steel during continuous cooling. J Mater Res. 2012;27(21):2779-89.

26. Shiga C, Yasuda HY, Hiraoka K, Suzuki H. Effect of the Ms temperature on residual stress in welded joints of high-strength steels. Weld World. 2010;54(3-4):71-9.

27. Liu C, Zhao Z, Northwood DO, Liu Y. A new empirical formula for the calculation of Ms temperatures in pure iron and super-low carbon alloy steels. J Mater Process Technol. 2001;113(1-3):556-62. 